\title{
Sociodemographic profile and Psychiatric diagnosis in attempted suicide.
}

\author{
Kafle B1, Bagale $\mathbf{Y}^{2}$, Dhungana $\mathbf{M}^{1}$
}

\begin{abstract}
1.Lecturer, Department of Psychiatry, Devdaha Medical College and Research Centre, Rupandehi, Nepal 2. Nursing Instructor, Devdaha Medical College, Rupandehi, Nepal
\end{abstract}

E-mail *Corresponding author: kafle_bikram@hotmail.com.

\section{Abstract}

Introduction: The presence of a mental disorder is an important risk factor for suicide. Attempted suicide is one of the major emergencies in psychiatry. Suicide attempts are considered to be the best predictors of an eventual completed suicide. Data of patients presenting with attempted suicide is scanty in Nepal.

Objective: The aim of the study was to explore the socio-demographic and psychiatric diagnosis of the patients with suicidal attempt

Method: The study population included those patients who were admitted and being managed for attempted suicide and brought for psychiatric evaluation during the period of one year (1st July 2015-30 June 2016) at Devdaha Medical College and research institute, Nepal. Each patient underwent a detailed psychiatric evaluation by a consultant psychiatrist once they were medically stable. Details including socio-demographic data, psychiatric diagnosis, was tabulated and analyzed using SPSS-16.

Result: Among the total patients (N=75), 68\% were in the age group 20-39 years. . Majority of the cases were female (78.7\%).53.3\% cases were married and majority were from Hindu religion. Most common method of attempted suicide was by poisoning and was by intake of Organophosphorous. Adjustment disorder(44\%) and Depression(24\%) were the most common psychiatric diagnosis. Marital dispute (22.7\%) and family dispute $(17.3 \%)$ and were the most common psychosocial precipitant.

Conclusion: Attempted suicide is widely prevalent on younger age group. It is usually by poisoning and the use of Organophosphorus compound is most common in our setting and is commonly associated with adjustment disorder. Hence, psychiatric care is essential for these patients.

Keywords: Attempted Suicide, poisoning, Adjustment Disorder

\section{INTRODUCTION}

The presence of a mental disorder is an important risk factor for suicide. Every year more than 800000 people take their own life whole over the world and there are many more people who attempt suicide. Every suicide is a tragedy that affects families, communities and entire countries and has long-lasting effects on the people left behind. Suicide occurs throughout the lifespan and was the second leading cause of death among 15-29year-olds globally in 2012. Suicide is a serious public health problem; however, suicides are preventable with timely, evidence-based and often low-cost interventions. It has been estimated that suicide attempts can be up to 1040 times more frequent than completed suicides. 1

In 1998 suicide represented $1.8 \%$ of the global burden of disease and it is expected to increase to $2.4 \%$ by the year 2020 . Suicide is among the 10 leading causes of death for all ages in most of the countries for which information is available. In some countries, it is among the top three 
causes of death for people aged 15-34 years. In the year 2020, approximately 1.53 million people will die from suicide based on current trends and according to WHO estimates 10 to 20 times more people will attempt suicide world wide .This represents on average one death every 20 seconds and one attempt every 1-2 seconds. 2,3 It is generally acknowledged that over $90 \%$ of those who committed suicide had a psychiatric diagnosis at the time of death. Underlying mental illness such as Depression, Adjustment Disorders, Schizophrenia, are the common diagnosis. ${ }^{4,13,14}$

Suicide is a fatal act of self-injury (self harm) undertaken with more or less conscious self destructive intent. ${ }^{19}$. Attempted suicide is defined as a potentially self injurious action with a non-fatal outcome for which there is evidence, either explicit or implicit that the individual intended to kill himself or herself. The action may or may not result in injuries. ${ }^{5}$

Financial difficulties, psychosocial problems, failure in exams, defamation are the major stressors that lead to suicide in males. Females found harassment, family problems, diseases, unemployment etc. as the major stressors. Consumerism, spending beyond resources pushing people in to debt is claimed to be major factor. Low frustration tolerance, problems in education system, parenting attitudes, weakening protective values of social institutions like family, increased use of alcohol all contributes to the stressor ultimately leading to suicide. ${ }^{7}$

It has been seen that suicide among young adults was associated with parameters such as relationship issues, unemployment, insufficient education as well as alcohol and drug misuse and it has been further escalating on exposure to stress. ${ }^{8}$

\section{MATERIAL AND METHOD}

This cross-sectional descriptive study based on the interview of the patients referred to the Department of Psychiatry at Devdaha Medical College And Research Institute. The study population included all those patients who were admitted and being managed for attempted suicide and brought for psychiatric evaluation during the period of one year (1st July 2015- 30 June 2016). Each patient underwent a detailed psychiatric evaluation by a consultant psychiatrist . Psychiatric diagnoses were considered as per ICD-10 criteria .

There were total 75 patients with history of attempted suicide Details of these patients including socio-demographic data, psychiatric diagnosis considered was analyzed using SPSS16.

The patients who died after reaching the hospital and those died during the recovery phase from physical ill health following attempted suicide were excluded from the study.

\section{RESULT}

The study showed majority of the cases were from the age group 20-39 which constituted 51 $(68 \%)$ of the total cases followed by $21.3 \%$ in the age group of up to 20 . Majority $59(78.8 \%)$ cases were female while $16(21.3 \%)$ cases were male. $40(53.3 \%)$ cases were married while $35(46.7 \%)$ were unmarried. Hindu being the majority consisting $63(84 \%)$, followed by $5.3 \%$ (4) by Christian. 26(36\%) cases were from Tharu caste followed by Chhetri 17(22.7\%). Poisoning was the most common method of attempted suicide $67(89.3 \%)$ followed by hanging $8(10.7 \%)$.

Regarding the psychosocial precipitating factors, almost $22.7 \%$ had marital dispute, followed by family dispute $(17.3 \%)$, relationship problem $(14.7 \%)$ and exam failure (10.7\%). In $17.3 \%$ of the situation, no significant precipitating factors could be recognized.

Around $90 \%$ used pesticides as the means of self-poisoning; Organophosphorus compound was the most common pesticide used(80.59\%).

Regarding psychiatric diagnosis in people attempting suicide, $44 \%$ cases had Adjustment disorder, followed by $24 \%$ cases of Depression. $13.3 \%$ cases had substance dependence. schizophrenia and personality disorder both including $6.7 \%$ cases and $5.3 \%$ cases of bipolar affective disorder. 
Table no. 1: Socio-demographic distribution $\underline{(\mathrm{N}=75)}$

\begin{tabular}{|c|c|c|c|}
\hline Variables & & $\begin{array}{l}\text { Frequency } \\
(\mathrm{n}=75)\end{array}$ & $\begin{array}{l}\text { Percentage } \\
(\%)\end{array}$ \\
\hline \multicolumn{4}{|l|}{ Age } \\
\hline & $0-19$ & 16 & 21.3 \\
\hline & $20-39$ & 51 & 68 \\
\hline & $40-59$ & 5 & 6.7 \\
\hline & $60+$ & 3 & 4 \\
\hline \multicolumn{4}{|l|}{ Sex } \\
\hline & Male & 16 & 21.3 \\
\hline & Female & 59 & 78.7 \\
\hline \multicolumn{4}{|l|}{$\begin{array}{l}\text { Marital } \\
\text { status }\end{array}$} \\
\hline & Married & 40 & 53.3 \\
\hline & Unmarried & 35 & 46.7 \\
\hline \multicolumn{4}{|l|}{ Religion } \\
\hline & Hindu & 63 & 84.0 \\
\hline & Buddhist & 3 & 4.0 \\
\hline & Christian & 4 & 5.3 \\
\hline & Islam & 5 & 6.7 \\
\hline \multicolumn{4}{|l|}{ Caste } \\
\hline & Brahamin & 14 & 18.7 \\
\hline & Chhetri & 17 & 22.7 \\
\hline & Tharu & 27 & 36.0 \\
\hline & Muslim & 5 & 6.7 \\
\hline & Others & 12 & 16.0 \\
\hline \multicolumn{4}{|c|}{\begin{tabular}{ll|l}
$\begin{array}{l}\text { Type of } \\
\text { poison }\end{array}$ & \\
\end{tabular}} \\
\hline & $\begin{array}{l}\text { Organo- } \\
\text { phosphorous }\end{array}$ & 54 & 80.59 \\
\hline & Others & 13 & 19.40 \\
\hline \multicolumn{4}{|l|}{$\begin{array}{l}\text { Method of } \\
\text { attempt }\end{array}$} \\
\hline & Hanging & 8 & 10.7 \\
\hline & Poisoning & 67 & 89.3 \\
\hline \multicolumn{4}{|l|}{$\begin{array}{l}\text { Psycho- } \\
\text { social } \\
\text { factors }\end{array}$} \\
\hline & Marital dispute & 17 & 22.7 \\
\hline & Family dispute & 13 & 17.3 \\
\hline & $\begin{array}{l}\text { Relationship } \\
\text { problem }\end{array}$ & 11 & 14.7 \\
\hline & Exam failure & 8 & 10.7 \\
\hline & $\begin{array}{l}\text { Death of loved } \\
\text { ones }\end{array}$ & 8 & 10.7 \\
\hline & $\begin{array}{l}\text { Economic } \\
\text { problem }\end{array}$ & 5 & 6.7 \\
\hline & Unidentified & 13 & 17.3 \\
\hline
\end{tabular}

Table no. 2: Distribution of suicide attempters by pattern of current psychiatric disorders $\underline{(n=75)}$

\begin{tabular}{|l|l|l|}
\hline Psychiatric diagnosis & Frequency & Percentage \\
\hline Depression & 18 & 24.0 \\
\hline Adjustment disorder & 33 & 44.0 \\
\hline Schizophrenia & 5 & 6.7 \\
\hline Substance dependence & 10 & 13.3 \\
\hline Personality disorder & 5 & 6.7 \\
\hline BPAD & 4 & 5.3 \\
\hline
\end{tabular}

\section{DISCUSSION:}

In this study, majority of the cases with suicidal attempt were from the age group 20-39( 68\%). The similar findings were reported by studies conducted at India and Nepal .9, 10,11 This suggests that most of the productive age group in the society is highly vulnerable to suicidal attempt. Increased prevalence of Suicide attempt among young might be related to both individual and socioeconomic parameters such as relationship among family members, unemployment, insufficient education, and alcohol and drug misuse as documented in other similar studies. ${ }^{8}$ Female suicide attempters outnumbered male with male female ratio being 1:3.6. This finding is similar to the other studies $.9,12,13$ Female preponderance in this study could be accounted to the fact that females are often exposed to the stress and strain of day to day life in our society.

Majority of the cases were from married group which is similar to the finding of other studies. ${ }^{9}$ As culture strongly creates some stressors after the marriage of Nepalese females, marriage may make them more prone to suicide.

Poisoning was the most common method of attempted suicide and organophosphorous was the most common pesticide used which was similar to the findings of the studies 12,14. In south Asian countries organophosphorus is most commonly used due to easy availability and lack of strict legislation in the rural and agricultural areas, ${ }^{15}$ and Nepal is one of the agricultural country.

Adjustment Disorder 44\% ( $n=33)$ constituted the most common psychiatric diagnosis followed by Depressive disorder which is comparable to 
other studies $.7,16$ The next major psychiatric diagnosis contributing to attempted suicide cases were substance dependence especially alcohol dependent syndrome. Marital dispute, family conflicts, economic problem and family disputes were the major precipitating factors for the act in other studies as well. 13,7

Limitation of our study was being a hospital based cross-sectional study, our sample size was just 75, and our results cannot be generalized. Hence, large scale community study of prospective nature is required.

\section{CONCLUSION:}

Suicidal attempt is an important psychiatry emergency. It is widely prevalent on younger age group. It is usually by poisoning and the use of Organophosphorus compound is most common and is mostly associated with adjustment disorder and depression. Hence psychiatric care is necessary .

\section{REFERENCES:}

1. .WHO, SUICIDE FACTSHEET 2017.http://www.who.int/mediacentre/factsheets/ fs398/en/

2. World Health Organization. Suicide Prevention (SUPRE)

www.who.int/mental_health/prevention/suicide/s uicideprevent/en (accessed 5 February 2009)

3. Bertolote, J., Fleischmann, A. Suicide and psychiatric diagnosis: a worldwide perspective, World Psychiatry. 2002 Oct; 1(3): 181-185

4. Patel V. Mental health in low- and middleincome countries. British Medical Bulletin 2007; 81/82: 81-96

5. Moscicki, The Psychiatric Clinics of North America: Suicide.W.B.Saunders Company;2003; 504-513.

6. Benjamin James Sadock \& Virginia Alcott Sadock, Synopsis of Psychiatry, Ninth edition Pg 919

7. Baby,S., Haridas, M., Yesudas K; Psychiatric diagnosis in attempted suicide, Calicut Medical Journal 2006;4(3):e2 |.

8. Singh DP, Acharya RP. Pattern of poisoning cases in Bir Hospital. J Inst Med 2006;28:3-6.

9. Logaraj M, Ethirajan N, Felix JW, Roseline FW. Suicidal attempts reported at a Medical college. Hospital in Tamil Nadu. Indian I community Med 2005; 30: 136-137.

10. Ponnudurai $R$, Jayakar J, Saraswati $M$. Attempted suicide in Madras Indian J psychiatry 1986; 28: 59-62
11. Risal A, Sharma PP., Karkib R. Psychiatric Illnesses among the Patients Admitted for Selfpoisoning in a Tertiary Care Hospital of Nepal . Journal of Advances in Internal Medicine. 2013 ;2(3)

12. Bajracharya, MR., Manandhar, K., Deo, KK., et al. Age and Gender Distribution in Deliberate Self-poisoning Cases. Post Graduate Medical Journal of Nepal Academy of Medical Sciences 2008;8:44-9.

13. Bansal, PD., Barman, R. Psychiatric Morbidity and the Socio- Demographic Determinants of Deliberate Self Harm. Journal of Clinical and Diagnostic Research 2011;5:601-4.

14. Maskey, A, Parajuli, M., Kohli, SC., et al. Scenario of poisoning cases in adults admitted in Manipal Teaching Hospital, Pokhara, Nepal. Nepal Journal of Medical Sciences 2012;1:23-6.

15. Ahmad, M., Rahman, FN., Ashrafuzzaman, M., et al. Overview of organophosphorus Compound Poisoning in Bangladesh and medico legal aspects related to fatal cases. JAFMC 2009;5:415.

16. Galgali, R.B., Sanjeev, Rao, Ashok.M.V, Appaya.P and Srinivasan.K, Psychiatric Diagnosis of Self Poisoning Cases a General Hospital Study. Indian Journal of Psychiatry. (1998) 40(3) 254-259

17. Bhatia MS, Aggarwal NK, Aggarwal BB. Psychosocial profile of suicide ideators, attempters and completers in India. Int J Soc Psychiatry 2000;46:155-63

18. Das PP, Grover S, Avasthi A, Chakrabarti S, Malhotra S, Kumar S. Intentional self-harm seen in psychiatric referrals in a tertiary care hospital. Indian J Psychiatry 2008;50:187-91

19. New oxford textbook of psychiatry, second edition, page 951. 